\title{
IGUALDADE PARA TODAS: ESTRATÉGIAS PARA POLÍTICAS PÚBLICAS E AÇÕES DO MOVIMENTO
}

\author{
Miriam Nobre \\ SOF - Sempreviva Organização Feminista, São Paulo, Brasil
}

\begin{abstract}
Resumo: As políticas públicas para o enfrentamento às desigualdades de gênero tendem a ser mais efetivas, segundo a ONU Mulheres, quando se utilizam da estrutura de direitos humanos para relacionar a política e a economia, ampliar a noção de trabalho e resgatar o princípio da universalidade. Ainda que essa estratégia possa funcionar para instituições multilaterais e Estados ela é insuficiente para a construção de agendas desde os movimentos feministas. Ao se utilizarem de referências como a economia feminista e ecológica na realização de alternativas coletivas, estes movimentos feministas constituem sujeitos políticos que co-constroem as políticas públicas que revertem as desigualdades.
\end{abstract}

Palavras-chave: Gênero; economia; feminismo; Nações Unidas (ONU); políticas públicas.

Em 2015, a ONU Mulheres lançou o relatório Progresso das Mulheres no mundo 2015-2016: Transformar as economias para realizar direitos (tradução da autora). O documento mostra que houve um avanço na visão desse organismo em relação à estratégia de transversalizar gênero (gender mainstream), predominante nos anos 1990. Além do mais, propõe uma agenda de prioridades que pode se constituir como um patamar mínimo para políticas públicas de fortalecimento das mulheres e enfrentamento das desigualdades de gênero.

No documento, a ONU Mulheres reconhece a importância da atuação dos movimentos feministas para a concretização dessas políticas, porém sugere a centralidade dos direitos humanos como estratégia para lidar com os desafios colocados o que, como veremos, é insuficiente.

\section{Antecedentes: a estratégia de transversalizar gênero}

A estratégia de Gender Mainstream emerge no final dos anos 1980 e demorou a se difundir. A partir da Conferência Mundial sobre Mulheres das Nações Unidas em Pequim

CC) (†) Esta obra está sob licença Creative Commons. 
1995 essa proposta foi ganhando importância nos altos níveis de decisão política nacional e internacional.

O contexto em que se desenvolve são as políticas de ajuste estrutural impostas pelas instituições financeiras multilaterais nos anos 1980 aos países endividados e à beira da insolvência graças ao aumento unilateral das taxas de juros. Sua implantação provocou um desastre na capacidade de os governos nacionais responderem às necessidades básicas de suas populações.

O aumento da pobreza em números absolutos foi tão grande que as próprias instituições tiveram que reorganizá-las em uma nova fase: a do ajuste estrutural humanizado, em que políticas sociais compensatórias buscavam aplacar os estragos mais drásticos. Essas políticas em geral se davam pela transferência monetária acompanhada da prestação de serviços privados, já que a reestruturação dos Estados nacionais fragilizados não se colocava na agenda.

Nesse momento o debate sobre as mulheres ganhou importância. As mulheres eram consideradas as mais vulneráveis, as mais pobres entre os pobres. Mas também aquelas capazes de gerir, por meio de trabalho não remunerado realizado em casa e nas comunidades, as necessidades que Estado e setor privado nem se propunham nem conseguiam responder. Nesse contexto, as especialistas em gênero são convocadas a fornecer análises que olhassem as mulheres e as convocassem ao esforço de humanização do ajuste. Tal processo criou as bases para a chamada globalização da economia, a criação de instituições e regras que assegurem aos capitais transnacionais um campo de atuação sem impedimentos para a realização de lucros, subordinando, a esta lógica, legislações e políticas nacionais.

Já no início dos anos 2000 , às críticas sobre as políticas de ajuste estrutural humanizado começaram a se acrescentar críticas a um processo de empobrecimento analítico e metodológico da estratégia de gender mainstream. Hilary Standing (2007), por exemplo, considera que a estratégia passou por um processo paradoxal e simultâneo de superpolitização e despolitização. Em um momento de institucionalização e perda de radicalidade do movimento feminista, transfere-se aos operadores de políticas públicas a transformação das relações de gênero. Por outro lado, a estratégia se concretiza por meio de ferramentas técnicas "industriais", "de massa", que tendem à simplificação e à descontextualização (checklists, toolkits...).

A despolitização observada decorre da necessidade de fornecer uma orientação precisa (orderly route map) a pessoas ocupadas e de realidades institucionais diversas (doadores, governos nacionais, locais), o que descontextualiza e banaliza as relações de poder em que gênero se insere (Hilary STANDING, 2007). Além do mais, a concretização da estratégia nunca chegou a tocar núcleos duros como as políticas macroeconômicas.

\section{Uma nova estratégia}

Os debates sobre a crise e as políticas de ajuste ganharam nova dimensão quando, especialmente a partir de 2008, passaram a fazer parte da realidade do norte geopolítico. Há muitos anos as latino-americanas desenvolvem formas criativas e coletivas de lidar com a crise da reprodução social, que está na base da sociedade capitalista. As respostas dos Estados nacionais e as recomendações das instituições financeiras multilaterais à crise do capital financeiro que estourou em 2008 ampliaram a potência dessas alternativas. Agora são afro-americanas que cultivam hortas em terrenos baldios de grandes cidades e catalãs que compartilham cuidados e tarefas da reprodução em bancos de horas. A ampliação no alcance e na radicalidade das alternativas construídas por mulheres organizadas em

646 Estudos Feministas, Florianópolis, 24(2): 645-652, maio-agosto/2016 
movimentos sociais demandam uma nova estratégia por parte das Nações Unidas.

A análise e a agenda propostas pela ONU Mulheres no relatório citado reconhecem que os avanços em termos legais ocorridos nos últimos 20 anos devem ser acompanhados de ações que garantam sua efetividade na vida cotidiana. Para tanto, partem de duas considerações que alteram significativamente os marcos das políticas de enfretamento das desigualdades de gênero. Não se trata somente de incluir as mulheres em serviços que funcionam mal, nem reduzir desigualdades entre mulheres e homens pela piora das condições dos homens, ou pelo aumento das desigualdades entre mulheres.

A referência dos direitos humanos que se plasmam em tratados internacionais firmados pela maioria dos Estados nacionais permite relacionar a política e a economia, ampliar a noção de trabalho e resgatar o princípio da universalidade. Dessa forma, aproximam-se de uma crítica à organização da sociedade, tendo como centro a economia reduzida aos interesses do capital, o trabalho considerado como social, o social visto como complementar, atuando onde o econômico falha. Ao contrário, considera que políticas redistributivas criam condições para a retomada da atividade econômica. Experiência esta que realizamos no Brasil com a política de valorização do salário mínimo, que dinamizou o mercado de consumo local e de produtos básicos, ao mesmo tempo em que reduziu desigualdades salariais entre mulheres e homens.

O relatório questiona a política macroeconômica que se restringe à política monetária de controle da inflação e de manutenção das condições de pagamento dos juros da dívida pública. Assim, aproxima-se de um questionamento da relação entre Produto Interno Bruto e dívida pública como indicador da saúde da economia de um país. Tal indicador tem valorações diferentes conforme o país em questão. Enquanto a lei da chamada "responsabilidade fiscal" dá munição à crise política que vivemos no Brasil, os Estados Unidos seguem com alto endividamento. As chamadas políticas de austeridade têm implicado o corte de gastos sociais e o aumento da precarização das relações de trabalho, sobretudo para as mulheres.

O relatório amplia a noção de trabalho para além do trabalho assalariado, que está presente, por exemplo, nos Objetivos de Desenvolvimento do Milênio (ODMs). Um dos indicadores para se atender ao Objetivo $n^{\circ} 3$ - "Promover a igualdade entre os sexos e a autonomia das mulheres" - refere-se à proporção de trabalhadoras assalariadas no setor não agrícola como medida de magnitude inversa do trabalho feminino não remunerado (IPEA e SPI/MP, 2014, p. 53). Porém, em uma leitura estrita desse indicador, um país em que camponesas desalojadas de suas terras em razão de um conflito armado trabalham em maquillas, em condições de superexploração, estaria mais perto de promover a autonomia econômica das mulheres que aqueles nos quais elas seguem produzindo em suas terras.

A agenda proposta no relatório da ONU Mulheres supera essa noção de trabalho restrita ao trabalho assalariado e olha não apenas para o trabalho produtivo, como também para o trabalho reprodutivo e de cuidados não só das crianças, mas de pessoas idosas e em situação de vulnerabilidade. Dessa forma, inclui o acesso das mulheres a ativos como terra, equipamentos e condições de produção, bem como para a distribuição da infraestrutura, o modo como a cidade se organiza e a multiplicidade de atividades econômicas realizadas pelas mulheres.

A proposta do relatório é comprometer os homens e concretizar políticas públicas de apoio à reprodução social. Assim, vai além do modelo de conciliação trabalho-família predominante em instituições multilaterais. O discurso da conciliação não questiona a responsabilidade prioritária das mulheres pelo trabalho de cuidados e nem a transferência para elas de todo o custo da reprodução social. Procura tornar possível a dupla presençaausência das mulheres no mundo da casa e do trabalho remunerado em um contexto de 
enorme sobrecarga, tensão física e emocional assumidas pelas mulheres individualmente (Cristina CARRASCO, 2003). Os limites impostos pela conciliação trabalho-família estão subentendidos na análise dos motivos pelos quais as mulheres "escolhem" (entre aspas no texto original) determinados trabalhos menos valorizados (UN WOMEN, 2015, p. 33).

Outra mudança relevante é a retomada da universalidade no acesso aos serviços públicos como princípio. A Seguridade Social é enfatizada como saída à vulnerabilidade e à precariedade. $O$ acesso de todas pode se dar pela combinação de modelos contributivos e não contributivos, a fim de que não se reproduzam ou se acirrem as desigualdades existentes no período laboral. A agenda de políticas propõe que sejam estabelecidas formas de contagem para períodos em que as mulheres se dedicaram ao trabalho não remunerado de cuidado e nos quais não puderam contribuir com o sistema. Outra proposta é não cobrar taxas de água e saneamento básico e substituí-las por financiamento coletivo. O aprendizado resultante da privatização dos serviços de água nos anos 2000 é de que causou a rápida deterioração das condições de vida das pessoas na África do Sul, mas também resultou na sublevação e na organização popular em Cochabamba na Bolívia.

\section{Ambiguidades e limites no financiamento das políticas}

A análise das políticas macroeconômicas no relatório reconhece que as formas de arrecadação e destinação dos recursos públicos têm um viés de gênero. O documento resgata como a reestruturação da dívida pública no Equador, em Lesoto e na Tailândia liberou recursos para a proteção social. No entanto, insiste em propor o endividamento como forma de acesso a recursos para o financiamento das políticas. Embora questione os mecanismos que as corporações transnacionais utilizam para evadir riquezas, não extrai mais consequências da pergunta "por que os países necessitariam endividar-se?" Também não questiona a forma como o mecanismo da dívida aprisiona os Estados nacionais à imposição de políticas preconizadas pelo Banco Mundial e pelo Fundo Monetário Internacional (FMI), ao estabelecimento de acordos de "livre" comércio com os Estados Unidos e a União Europeia e à chantagem do capital financeiro transnacional. Muito menos reflete, como nos propõe a ecofeminista Ariel Saleh (2009), sobre o fato de que o capitalismo é construído sobre uma dívida social ao explorar os trabalhadores, uma dívida corporificada nas mulheres - pelo trabalho reprodutivo não remunerado que realizam - e uma dívida ecológica com camponeses e indígenas pela apropriação de suas terras e meios de vida.

O reordenamento dos gastos passa por uma redução dos gastos militares. Essa premissa é bastante interessante, porém deve ser ampliada para considerar a redução dos gastos com segurança interna, sistemas de vigilância e políticas "antiterroristas". O documento não expressa preocupações tais como em relação à indústria do medo alimentada pela mídia, pelas empresas de segurança privada e pelos fundamentalismos religiosos - e que é parceira do sistema industrial prisional. No Brasil, nos tornamos mais atentas ao fato de que os gastos do governo do estado de São Paulo com a abertura de vagas em presídios são bastante superiores aos gastos com a educação graças à informação trazida à tona pela resistência de alunas, familiares e professores ao fechamento de salas de aula (Wanderley SOBRINHO, 2015). Observa-se que as taxas de desemprego entre os pobres e não brancos são manejadas pela prisão de milhares de pessoas. As mulheres, mães e professoras são responsabilizadas pela violência cotidiana e pela ameaça terrorista, já que seriam elas que transmitiriam a "disfuncionalidade" aos garotos por elas socializados. 
Por fim, o documento aponta a utilização de recursos naturais como forma de arrecadação de divisas. Chama atenção para a total ausência de crítica à divisão internacional do trabalho e ao papel do mercado de commodities que, ao manipular seus preços nas bolsas de Londres e de Nova York, termina por impor uma intensa exploração da natureza, sobretudo em países do sul global. Sabe-se que as empresas mineradoras estão no centro de inúmeros conflitos nos territórios em todas as partes do mundo e que sua lógica de extração dos minérios se fundamenta mais na manutenção de altas remunerações a seus acionistas frente às oscilações nos preços do que no atendimento de necessidades materiais - já por si só questionáveis, dado o mecanismo de obsolescência programada, em que os produtos já saem das fábricas com duração determinada.

\title{
Agenda para quem?
}

A ONU Mulheres reconhece que a incidência das organizações de mulheres, em aliança com movimentos sociais mistos e com gestores públicos e pesquisadores, é fundamental para a concretização das políticas de fortalecimento das mulheres. Por isso, propõe o apoio a essas organizações e a criação de mecanismos de acompanhamento das políticas como parte de sua agenda. Porém, dá um passo além ao sugerir como referência para a agenda desses movimentos a estrutura dos direitos humanos:

\begin{abstract}
O trabalho com comunidades marginalizadas deve partir da realidade concreta da vida das mulheres e criar o espaço para uma reflexão crítica e compartilhar experiências. Ao fazer isso, ativistas podem não usar a linguagem dos direitos humanos como ponto de partida, preferindo usar noções como equidade e dignidade que ressoam melhor em grupos de base de mulheres. (UN WOMEN, 2015, p. 42, tradução da autora)
\end{abstract}

Esse trecho nos causa a sensação de que, ainda que a linguagem e os tratados de direitos humanos não sejam de fácil apropriação, poderiam criar uma unidade de ação e articular o discurso, desde que mediados por aquelas que os dominam, em geral, profissionais de ONGs. Abre-se, portanto, as vias para a institucionalização e despolitização do movimento feminista vivenciada nos anos 1990 (Sonia ALVAREZ, 2014).

Dois exemplos ilustram esse risco. Um é o tema das alianças. Uma das potências do movimento feminista nos anos 2000 foi ser parte integrante do movimento antiglobalização neoliberal, apresentando uma visão feminista sobre o conjunto das preocupações desse movimento (livre comércio, militarização, justiça climática).

Nesse período, a aliança não se caracteriza pelo acordo em torno de pontos consensuais, mas em uma contaminação de agendas. Por exemplo, a aliança estratégica entre Marcha Mundial das Mulheres e Via Campesina resultou em novas sínteses na abordagem da soberania alimentar, incorporando questões como a partilha do trabalho doméstico, o reconhecimento de saberes acumulados pelas mulheres na produção e no preparo dos alimentos, a resistência à violência contra as mulheres perpetrada por companheiros e acirrada em contextos de "açambarcamento" de terras. A aliança entre movimento feminista e movimentos sociais, protagonizada pelas mulheres desses movimentos, é de ordem bastante diferente das alianças táticas entre movimentos e gestoras públicas, ou de acordos de trabalho comuns entre movimentos e organismos de cooperação internacional.

Outro tema são os estreitos limites demarcados pelos direitos humanos na análise do atual momento de acumulação capitalista, marcado pela despossessão do trabalho e da natureza. Por exemplo, não se pode questionar o direito de pessoas transgêneras à terapia hormonal fornecida gratuitamente pelos serviços públicos de saúde. Mas utilizando referências analíticas como o ecofeminismo, por exemplo, é possível desconfiar que a 
medicalização impulsionada pela indústria farmacêutica seja a principal via de saída para a binaridade dos gêneros.

\section{Perspectivas desde o movimento das mulheres}

Os movimentos feministas buscam outras referências para responder às perguntas apresentadas pelo relatório. Por que ainda ocorrem retrocessos nas legislações quanto aos direitos das mulheres? Por que legislações favoráveis a estes direitos não se realizam na prática?

Segundo o documento, as legislações em relação aos direitos das mulheres nas famílias tiveram ritmos de avanço diferentes nos países. Foram mais lentos nos países com influência islâmica e com riscos de retrocesso, sobretudo nos governos saídos das revoltas populares, conhecidas como primavera árabe. Os riscos de retrocessos conservadores se sentem em outros países, não no direito da família, mas, por exemplo, na resistência ao debate sobre gênero nas escolas, vetado em legislações municipais no Brasil, questionado na porta das escolas na França.

Além de setores conservadores muçulmanos, setores católicos e evangélicos, muitas vezes em aliança, organizam-se para ocupar os legislativos e atuar sobre as políticas públicas. Pode ser que o resultado de sua articulação e o acesso a recursos lhes confira um maior peso no legislativo do que sua influência real na sociedade. Nesse caso, o debate que se apresenta é o da necessidade de uma reforma política que vise despatriarcalizar as estruturas de Estado. Mas também há o aumento de sua influência na sociedade. Esses setores representam uma resposta conservadora ao acirramento do individualismo, à ausência de referências comunitárias e à insegurança quanto ao futuro. Cabe a nós, como parte do movimento feminista, construir referências coletivas em resposta às necessidades básicas, que não são só materiais, mas de afeto, de respeito e de expressão política.

Entre as leis que não se realizam na prática estão aquelas que asseguram o direito das mulheres à herança. Como o relatório reconhece, muitas vezes as mulheres não fazem valer seus direitos porque não se sentem seguras para romper com suas famílias. O avanço na oferta de empregos de qualidade e a proteção social reduz a dependência das mulheres das redes familiares para sua segurança econômica. No entanto, mulheres que gozaram de autonomia econômica em boa parte de sua vida, mesmo em países considerados desenvolvidos, se veem desamparadas em momentos de vulnerabilidade. Quem as acompanhará ao serviço de saúde quando necessitem de um tratamento debilitador como a quimioterapia? Sua aposentadoria será suficiente para pagar um centro de acolhimento de idosos que respeite sua individualidade? Cabe a nós construir experiências de cuidado coletivo que não nos confinem nas obrigações familiares em moldes patriarcais nem nos mitos do amor romântico.

\section{Economia feminista e ecológica como referência}

As tarefas que a organização da vida nos apresentam hoje nos remetem a referências de análise e de construção de agendas comuns que vão além da estrutura de direitos humanos, como podem ser a economia feminista e a economia ecológica

A economia feminista descreve os processos socioeconômicos reconhecendo que somos interdependentes - dependemos física e emocionalmente do tempo que outras pessoas dedicam a nós - e ecodependentes - somos uma entre as muitas espécies que habitam o planeta e obtemos da natureza o que necessitamos para estar vivos: água, alimentos, energia (Yayo HERRERO, 2014). O atual modelo socioeconômico se organiza por normas heteropatriarcais que instauram o conflito capital-vida. Portanto, as respostas à 
inter e ecodependência se fundam nas desigualdades: as mulheres dedicam mais tempo e disposição emocional ao cuidado que os homens; os cuidados são transferidos a mulheres negras e migrantes na forma de trabalho precário; e os tempos e condições de regeneração da natureza são desconsiderados a tal ponto que a ganância da mineradora Samarco pôde causar a morte de pessoas e da bacia hidrográfica do Rio Doce.

O atual quadro coloca para a economia feminista a necessidade de elaborar políticas que "combinem o urgente e o importante: dar respostas imediatas à crise de reprodução social e afrontar a crise sistêmica" (Amaia OROZCO, 2014, p. 171). Isso implica reduzir as desigualdades sem criar outras, desvelar o caráter político de cada decisão econômica, assegurando que as pessoas e os setores em posição subordinada na sociedade possam se constituir nos sujeitos políticos que revertam esta subordinação.

Os nexos entre produção e reprodução social têm sido o objeto de atenção da economia feminista. Essa perspectiva se traduz na prioridade à responsabilidade social e compartilhada do cuidado e na valorização dos bens e serviços fundamentais para a manutenção da vida, que não são objetos de transação monetária, como a produção para o autoconsumo, de modo que a troca seja entendida como prática de comunidades tradicionais ou recriada em experiências de economia solidária.

Além disso, a fim de assegurar a autonomia econômica no modelo de economia hegemônico é fundamental o acesso à renda monetária. O desafio é combinar o "urgente" - ampliar o acesso à renda - com "o necessário" - rejeitar a expansão da economia de mercado para todos os domínios da vida. Apesar das ficções criadas pelo poder político do capital financeiro, a renda monetária deveria ser uma expressão da riqueza real criada pelo trabalho humano. Como redistribuí-la é também parte do enfrentamento do conflito capital-trabalho, sendo o trabalho humano uma das expressões da vida.

A pergunta central do capítulo "Igualdade substantiva para as mulheres: o desafio das políticas públicas" (tradução da autora) é: como aproximar a estrutura de direitos humanos (tratados internacionais firmados pela maioria dos Estados nacionais) das políticas públicas de fortalecimento das mulheres e de enfrentamento das desigualdades de gênero que tornam concretas as melhorias na vida das mulheres?

A pergunta que anima muitas feministas organizadas em movimentos é: como desenvolver práticas coletivas contra-hegemônicas à ordem social e econômica que criem outros paradigmas para uma vida que vale a pena ser vivida? É a força motora desta ação que empurra os Estados a propor e a concretizar políticas públicas que se fundem na liberdade e na igualdade para todas.

\section{Referênclas}

ALVAREZ, Sonia. "Neoliberalismos e as trajetórias dos feminismos latino-americanos". In.: MORENO, Renata (Org.) Feminismo, Economia e Política. São Paulo: SOF, 2014, p. 23-28.

CARRASCO, Cristina. "Sustentabilidade da vida humana: um assunto de mulheres?". In: FARIA, Nalu e NOBRE, Miriam (Orgs.). A produção do viver: ensaios de economia feminista. São Paulo: SOF, 2003, p. 11-49.

HERRERO, Yayo. "Economía ecológica y economía feminista: un dialogo necesario". In.: CARRASCO, Cristina (Org.). Con voz propia. La economía feminista como apuesta teórica y política. Madrid: La Oveja Roja, 2014, p. 219-238.

INSTITUTO DE PESQUISA Econômica Aplicada (IPEA) e Secretaria de Planejamento e Investimento Estratégico (SPI/MP). Objetivos de Desenvolvimento do Milênio. Relatório Nacional de Acompanhamento. Brasília: IPEA, 2014.

OROZCO, Amaia. "Crisis multidimensional y ajuste feminizado: retos y oportunidades". In.: 
CARRASCO, Cristina (Org.). Con voz propia. La economía feminista como apuesta teórica y política. Madrid: La Oveja Roja, 2014, p. 171-192.

SALLEH, Ariel. "Ecological Debt: Embodied Debt". In.:

(Ed.) Eco-sufficiency and Global Justice. Women write Political Ecology. London: Pluto Press, 2009, p. 1-40.

SOBRINHO, Wanderley. "Gestão Alckmin gasta quase 5 vezes mais com detento do que com aluno". Brasileiros, 10 out. 2015. Disponível em: <http://brasileiros.com.br/2015/10/gestaoalckmin-gasta-quase-5-vezes-mais-com-detento-que-com-aluno/> . Acesso em: 10/02/ 2016.

[Dossiê proposto em 6/07/2015,

apresentado em 12/01/2016

aceito para publicação em 29/02/2016]

Equality for All: Strategies for Public Policy and Social Movement Actions

Abstract: According to UN Women, public policies aimed at reducing gender inequalities tend to be more effective when based on the human rights framework, with a view to linking politics and economy, widening the concept of work and rescuing the principle of universality Although this strategy can potentially function for multilateral institutions and States, it is insufficient for the construction of feminist movement agendas. Using references such as feminist and ecological economics in the construction of collective alternatives, these feminist movements constitute political subjects that co-construct political policy with the aim of reverting inequalities.

Keywords: Gender; Economy; Feminism; United Nations (UN); Public Policy 